\title{
THE CONTROL OF GLAZE-FIT BY MEANS OF TENSILE TEST SPECIMENS ${ }^{1}$
}

By F. H. RIDdie aNd J. S. LAIRD?

ABSTRACT

The selection of a suitable glaze for a particular body by usual inspection of a field of glaze trials is not sufficiently precise, and gives no indication of slow crazing tendencies.

A new method of selecting glazes depends on the effect of a glaze on the strength of a porcelain tensile test specimen. The best fitting glazes increase the strength while poorer ones decrease it. Glazes which craze weaken the specimens very markedly. Results obtained with various glazes on one fire porcelain are given.

\section{Introduction}

When a glaze is selected by a systematic study of a tri-variant system, it is found as a rule that within a field of considerable area the glazes appear equally suitable, that is, the composition may be varied considerably without developing crazing, shivering, under-maturing or over-firing. The selection of the best glaze within this field has been largely a matter of judgment, and the best glaze could not be assumed to be the one most nearly central in the field of good glazes. It is frequently the case that a glaze which appears satisfactory when newly fired will develop crazing on standing. This is particularly troublesome in the case of bright glazed wall tile which have an unfortunate habit of crazing anywhere from a month to several years after being cemented up in a wall, even though they may have shown no signs of crazing when newly fired or even when stored in air for a long time.

Attempts have been made to devise tests which would indicate quickly any tendency for an apparently suitable glaze to develop crazing. The tests have usually involved subjecting the specimens to rapid variations in temperature, much wider than those to which they would ever be subjected in use. These methods while of value for the particular products for which they have been devised are not of very general applicability.

A new direct method for comparing different glazes as regards fit has been devised in this laboratory, based upon the effect which a glaze exerts on the strength of a porcelain tensile test specimen.

\section{Preparation of Specimens}

Test specimens of diameters $0.4-0.5$ inch are used, similar to those used in the tensile testing of metals, modified as necessary on account of the difficulty in loading a material of the degree of brittleness of porcelain.

${ }^{1}$ A contribution from the Research Laboratories of the Champion Porcelain and Jeffery-Dewitt Insulator Companies.

2 Received April, 1922. 
They are formed by turning in the green state, and after glazing and firing are broken on an ordinary cement testing machine, as described in detail in an article, "The Determination of the Tensile Strength of Porcelain." 1 The preparation of the specimens differs from that of test specimens for determining the tensile strength of porcelain bodies in that they are glazed all over (except the ends) while at least the central portions of the tensile strength specimens are left unglazed.

A number of specimens are made up from one body, glazed with the various glazes to be compared and fired together all in the same sagger when possible and in a large kiln. At least ten specimens glazed with each glaze should be prepared and tested.

\section{Effect of Glaze on Strength of Specimens}

The glazing of a small porcelain object such as one of these test specimens may (a) materially increase, $(b)$ have little effect on $(c)$ markedly decrease its breaking strength. These effects appear to be determined by the degree of success with which the glaze has been fitted to the body.

Thus, in the following series of tests the composition of a particularly good one-fire porcelain glaze maturing at cone 16-18 was modified by the addition of increasing amounts of a certain ingredient, so that while the maturing range of the glaze was not affected noticeably, crazing was developed with the higher members of the series.

The test specimens were taken from a large batch made mechanically, i. e., blanks were cut from pugged one-inch rolls, and turned to a definite size. All the specimens were fired in one sagger in a commercial kiln. Each result is the average strength of several specimens.

\section{TABLE, I}

Series of Cone 18 Glazes with Increased Crazing Tendencies

\begin{tabular}{lcl} 
Glaze used & $\begin{array}{c}\text { SrRenGry } \\
\text { Lbs. per sq. in. }\end{array}$ & \multicolumn{1}{c}{ Remarks on glaze } \\
No Glaze & 8,890 & $\ldots \ldots$ \\
Glaze 255 & 10,245 & Standard \\
Glaze 255 A & 9,135 & Very good \\
Glaze 255 B & 4,338 & Bright, but distintly crazed \\
Glaze 255 C & 3,592 & Bright, badly crazed \\
Glaze 255 D & 3,437 & Opaque, crazed
\end{tabular}

The falling off in strength with the development of crazing is very marked, dropping to only one-third with the poorest glaze. A marked decrease in strength is, however, shown by glaze $255 \mathrm{~A}$, which in appearance is equal to 255 , and from which it differs in chemical composition by only $1.25 \%$.

${ }^{1}$ Riddle and Laird, Proc. A.S.T.M., 21, 1050-56 (1921). Riddle and Laird, Jour. Amer. Ceram. Soc., 5, 385 (1922). 
The following table shows results with one-fire cone 13 porcelain with various glazes.

\begin{tabular}{ccc} 
& \multicolumn{2}{c}{ TABLE II } \\
Glaze no. & $\begin{array}{c} \\
\text { TENSILE STRENGTH } \\
\text { Lhs. per sq. in. }\end{array}$ & \multicolumn{1}{c}{ Remarks on glaze } \\
22 & 7,520 & Good bright glaze \\
16 & 6,954 & Good bright glaze \\
$691 \mathrm{D}$ & 6,590 & Somewhat pinholed \\
665 & 5,710 & Immature, mat \\
666 & 2,052 & Crazed, immature
\end{tabular}

Table III gives results with a number of cone 18 glazes none of which showed crazing by usual inspection but which showed marked differences by these tests. It may be noted that the glaze selected as a result of these tests has proved extremely satisfactory and reliable for use on spark plugs, the tensile strength tests being confirmed by impact tests. Glaze No. 666 was very white and of high covering power but weakened the body to which it was applied.

\begin{tabular}{ccl} 
& \multicolumn{2}{c}{ TABLE III } \\
Glaze no. & $\begin{array}{c}\text { SrRENGTH } \\
\text { Lbs. per sq. in. }\end{array}$ & \multicolumn{1}{c}{ Remarks on glaze } \\
644 & 10,876 & Good, slightly vesicular \\
255 & 10,324 & Good, slightly eggshell \\
665 & 10,178 & Very good \\
649 & 9,779 & Poor, vesicular \\
653 & 9,622 & Very good \\
647 & 9,622 & Good \\
646 & 9,578 & Poor, vesicular \\
648 & 9,454 & Poor, eggshell \\
652 & 9,382 & Good \\
664 & 9,200 & Poor, mat \\
650 & 9,184 & Good \\
645 & 9,033 & Poor \\
651 & 8,973 & Good \\
654 & 8,632 & Good \\
655 & 8,432 & Good \\
666 & 8,119 & Very good \\
663 & 7,552 & Poor
\end{tabular}

\section{Conclusions}

There can be no question as to the intimate relationship between the fit of the glaze and the strength of small glazed porcelain objects such as spark plugs, or with one or more small dimensions as rods, tubes, plates, etc. This relation probably holds true to a considerable extent for porcelain objects of any size or dimension, as for example high tension insulators. Failure of the glaze to fit, especially when the fit is so poor that crazing develops, produces strains in the surface of the porcelain so that failure 
occurs under a much smaller external load than when the porcelain is free from such strains. On the other hand proper selection of a glaze results in a strength notably greater than that of the unglazed ware, an increase which can not be referred with one-fire porcelain to increased vitrification of the body due to soaking in of the glaze.

No experiments along this line have been made with semi-porcelain or the unvitrified bodies used in bright glazed wall tile, but it seems probable that in these cases also this method could be successfully used in the selection of glazes.

Derzort, Micн. 